tion with catgut and section one-quarter of an inch be. low this; 6 , closure of the wound with a buried catgut stitch, and application of a collodion dressing. The entire operation can be performed on both sides in less than ten minutes, without any pain to the patient. The wound will heal so perfectly that no scar can be discovered.

The advantages of dealing with habitual criminals in this manner can be summed up as follows:

1. It would do away with hereditary criminals from the father's side.

2. Aside from being sterile the criminal would remain in his normal condition.

3. This method would protect the community at large without harming the criminal.

4. 'The same treatment could reasonably be suggested for chronic inebriates, imbeciles, perverts and paupers.

710 Sedgwick Street.

\title{
RECURRING GONORRHEA.
}

\section{BY HARRY GREENBERG, M.D.}

INSTRUCTOR IN GYNECOLOGY, WISCONSIN COLLEGE OF PHYSTCIANS AND SURGEONS. MILWALKEE, WIS.

V. F., single, merchant, aged 26 , consulted me on July 2, 1898 , for an attack of gonorrheal urethritis, and under treatment with potassium permanganate solution irrigations for one month, was discharged cured. He was then instructed to abstain from the use of alcohol in any form, and was warned against marrying for at least one year from date of discharge, as he was then engaged to be married to a refined young woman of this city.

On March 2, 1899, he again consulted me as to the advisability of marrying, and assured me that during all these months, he had noticed no discharge from his urethra, and at no time felt any inconvenience. He also stated - and I think truthfully-that he did not during that time partake of any alcoholic drinks, and had not indulged in sexual intercourse. Physical examination revealed nothing.

He was married one week later, and again consulted me in ten days from the date of his marriage, for a discharge from his urethra and all symptoms of acute gonorrheal urethritis, which diagnosis was substantiated by the microscope. Three days later his wife consulted me for burning urination and vaginal dis. charge, which on examination proved to be of gonorrheal infection, likewise substantiated by the microscope. This young woman I had treated for uterine displacement, and had examined her but two days previous to her marriage, and as $I$ at no time had occasion to doubt her innocence, the infection can be attributed to no other cause than that she contracted it from her husband.

This is but one of many similar cases that have come under my notice, but none, where I could so definitely attribute the recurring infection to an old and apparently cured gonorrhea.

This case is of interest in once more reviving the question: When may our patients, after cessation of the discharge from a gonorrheal urethritis, marry without fear of relapse and infecting the innocent woman? In an article in the Joursal of March 25, under the heading of "Treatment of Gonorrheal Urethritis," the author, after recommending a certain line of treatment, says that after the discharge ceases and micro-

scopic examination reveals no gonococci, the patient may be discharged and, in his own words, relapse is impossible without infection. The case above cited certainly does not warrant this, his positive assertion.

While it is true that many cases of gonorrheal urethritis suffer no relapse, it is also true, in many instances, that although the microscope will fail to show any gonococci in the urethral secretions, yet they exist latent in some of the folds of the urethra, harmless in their present state, but liable to regain their former virulence under favorable conditions, which a temporary congestion of the urethra will afford. Immoderate use of alcohol, and excessive venery-both conditions common in the newly-married -have the effect of producing a hyperemia of the sexual organs, and produce therefore a good nutrient medium for the latent gonococci to thrive on. It may also be possible that the gonococci, while harmless in their present position in the male urethra, after being deposited in the vagina, affording them a fresh soil, will again become virulent and produce a gonorrheal vaginitis, which will in return reinfect the man on a subsequent coition.

This same fact is also applicable in the female, after a gonorrheal vaginitis. I have observed, on examining prostitutes who had at some period been affected with gonorrhea, but were now apparently free from it, that they are nevertheless prone to infect the male uretbra with gonorrhea. I have also carefully investigated several cases where the man has contracted the infection from a woman who, before and after sexual intercourse with that man, was examined by me and no signs of gonorrhea could be detected. Evidently the latent gonococci in the folds of the vagina, after being deposited in the male urethra, began to thrive on the new soil and set up the inflammation.

545 E. Water St.

\section{RECURRENT RHEUMATIC IRITIS.*}

RECOVERY, WITH A SEGMENT OF THE IRIS FIXED WITHOUT APPARENT SYNECHIA, WITH NORMAL ACUITY

OF VISION AND WITHOUT INCREASE OF MYOPIA, IN PATIENT WITH MYOPIC ASTIGMATISM.

BY S. D. RISLEY, A.M., M.D.

Attending Surgeon Wills Eye Hospital; Professor of Diseases of the Eye, Philadelphia Polyclinic and College for Graduates in Medicine. PHILADELPHIA, PA.

Mr. A., aged 35 years, with well-marked rheumatic diathesis, has for several years been subject to recurring iritis of a severe type. I have treated him through three violent and persistent attacks and several milder exacerbations of the disease. The last and most violent came on as a simple hyperemia of the iris, with impaired visual acuity on Oct. 22, 1898. A full dilatation of the pupil was immediately secured, when it was discovered that the fundus presented a uniform fluffy appearance and that there was a fine exudate in the anterior portion of the vitreous. Notwithstanding active treatment addressed to his diathesis and to the local conditions, the eye developed a violent and painful attack of iritis of the parenchymatous type, which confined him to his room until the close of November, and he did not resume his business until the middle of January. The in-

* Read before the College of Physicians of Philadelphia-Section on Ophthalmology. 
jection of the eyeball slowly retired, and with it the infiltration of the vitreous and the inflammation of the uveal tract, until, on February 4, vision had risen once more to $6 / 6$, and the eye was white. The pupil was still too large as compared to the fellow eye, although a mydriatic had not been used for more than six weeks, and was pyriform, the long axis being vertical. The iris, however, reacted promptly to the change of light and shade, except at a small segment be. low, where it remains in a condition of semidilatation, and does not expand or contract. At date of present writing, March 18, the pupil is still larger than its fellow, and the lower segment is still fixed. No synechia can be made out, and there is apparently no atrophy of the iris fibers.

Dr. de Schweinitz, in commenting upon the etiol. ogy of the paralysis in his case, presented to the Section last October, remarks that, "evidently the nerveendings or filaments which supply the lower half of the iris have been permanently injured by the preceding inflammatory process."

As possibly throwing light upon the etiology of the paralysis in my own case, it is interesting to observe that on October 29, when the eye was steadily growing worse, I discovered, hanging in the anterior chamber, a translucent membrane appearing like a thin sheet of transparent gelatin. Its exact origin could not be made out, but it occupied the lower and outer quadrant, and appeared to extend from the outer angle of the anterior chamber diagonally inward to the vertical meridian, where it covered the lower and outer quadrant of the pupil and seemed to be attached to the surface of the iris at its lower half, just at the point where paralysis is now present. During dilatation, as in Dr. de Schweinitz' case, the pupil was entirely round. It should be borne in mind that the pupil was kept widely dilated for many weeks, and that during this time it was involved in a high grade of plustic, parenchymatous inflammation. It is therefore possible that the posterior surface of the iris is attached far back to the anterior capsule of the lens, and the absence of contraction and expansion may be due to this adhesion. I am inclined to think that this is the probable explanation, but if so, the adhesion is back of the iris, where it can not be seen, and can not therefore be demonstrated.

\section{Eorrespondence.}

\section{A Very Irregular "Regular.'}

New York City, A pril 3, 1899.

To the Editor:--The following letter speaks for itself. I violate no confidence in making it public. It was not addressed to me, nor indeed, except on the envelope, which I did not $\theta e \theta$, to any one else. It was shown to me as having been received by a government official, and was circulated on the authority of its writer-a "regular" physician of long standing :

, November, 1898.

My Dear Doctor:-Hoping and believing that you are alive and well, and not doubting that, for old acquaintance sake, you will entertain my message, I will speak briefly and without apology.

I was pained to read of the death of Geo. E. Waring, and all the more because I have the fullest assurances that bis death could have been prevented. Anc so of thousands who have died, or will have died, in the new regions coming under United States control as a result of the war. The obstacle to the employment of the remedy might be called by the mild name of professional conservatism, I suppose. However keenly one might regret that a really powerful sanitary or therapeuti agent were under the cover of a patent, nevertheless I would use it, if it were certain to save life. And I beg you to accept my personal and professional assurance that the remedy is a practical specific in all forms of fever and in nearly all cases of inflammation, gastric, hepatic, intestinal, pulmonary, etc.

The agent is the oxygen generated or rather evolved by the application of the - or - practically the same in operation and effect. I am perfectly aware of the apparent incredibility of the assurance, but I make the statement soberly, disinterestedly and in the fear of God. But what can I, a mote in creation, and with the weight of professional predilection, adverse to aught that is without the sphere or area of professional ethics, so-called, avail? . . . It seeme exceeding!y regrettable that so many in camp and hospital must die, when the deatbs need not occur.

I have no wish to lead in a reformatory raid, but I do believe that a line should be drawn in the ranks of the profession itself between the men who realize the dignity of medicine and the shallow sciolists like the author of the above letter, who is of the class which "practices allopathy or homeopathy," as its clients prefer, of which examples are by no means rare in physicians of recognized regularity. The letter-writer is not an illiterate; he does not outrage the English language nor exhibit the not uncommon evidences of ignorance that would shame a school boy. His chirography is commendable; his orthography unexceptionable; he expresses himself intelligibly, and is consequently more disreputable and dangerous than the ignoramus whom every one ridicules and avoids. $\mathrm{He}$ is a respectable member of society, and writing "in the fear of God," is probably a dignitary in a church, whose members, and not unlikely his pastor, give heed and weight to his utterances. Conscious of acting an objectionable part, he virtually accuses himself in excusing himself for having antagonized what he says "might be called by the mild name of professional conservatism." The harm that such a man does is incalculable. He announces as incontrovertible what laymen might be pardonable for accepting as such, and with humility that savors of sanctimony, he appeals for support by lamenting, "what can I, a mote in creation, and with the weight of professional predilection adverse to aught that is without the sphere o: area of professional ethice, so called, avail?"

Beside the dictum of this man, regularly certified to be doctoratus in medicine, Clara Barton's indorsement of electropoise as an "incalculable blessing, which has power to put a person to sleep and keep him asleep until satisfied nature awakes refreshed," is venial and of a par with this estimable, indefatigable but misguided woman's certificate as President of the American National Red Cross, that "We have tried Dr. 's blood and nerve remedy, and although the remedy has been in our hands but a short time, wo judge that the remedy has all the merits which are claimed for it. We shall continue its use, with the expectation that we shall be able to indorse it still more highly"; but when a man, presumably educated in the highest of all professions, writes: "I beg you to accept my personal and professional assurance that the remedy is a practical specific in all forms of fover and in nearly all cases of inflammation, gastric, hepatic, intestinal, pulmonary, etc.," and adds, "I am perfectly aware of the apparent incrediblity of the assurance, but I make the statement soberly, disinterestedly and in the fear of God," it is to be regretted that he can not be disciplined by expulsion from the ranks of the profession he dishonore, apart from the grief he causes the relatives and friends of the man whose death he signally deplores as preventable as well as "of thousands who have died or will have died in the new regions coming under United States control as a result of the war." But, however reprehensible, individual effort at exposure only serves to glorify the culprit as a victim of persecution and to dignify his work as heresy, so it is for the profession as a body to discountenance and disbar all such offenders. The A merican Academy of Medicine has sought to establish a pale of professional iner- 